\title{
Consistency of health-related quality of life among people living with HIV: Latent state-trait analysis
}

\author{
Marcin Rzeszutek ${ }^{1 *}$ and Ewa Gruszczyńska²
}

\begin{abstract}
Background: The aim of this longitudinal study was to examine the consistency of health-related quality of life ( $H R Q O L)$ among people living with HIV (PLWH) by breaking down the variance of repeated HRQoL measures into trait, state, and method components and to test the stability of HRQoL over time. In addition, we wanted to examine whether HRQoL trait components are related to personality traits, while controlling for selected sociomedical variables.
\end{abstract}

Methods: Three assessments were performed with a six-month lag on each assessment. Each participant filled out a World Health Organization (WHO) Quality of Life-BREF to assess HRQoL and a NEO-FFI to measure Big Five personality traits. Overall, 82 participants out of 141 (58.2\% of the initial sample) participated in all the assessments.

Results: The HRQoL among PLWH represented a stable trait to a somewhat greater extent than a situational variability, although the proportions were domain and time variant. More specifically, psychological domain appeared to be the most consistent, whereas social domain appeared to be the most prone to situational influences. The trait component of HRQoL was positively related to being in a relationship, being employed, and being extraverted, and negatively related to neuroticism, which altogether explained $26 \%$ of the trait variance.

Conclusions: HRQOL among PLWH is rather distinct from personality and socio-medical data, which indicates its uniqueness in a clinical practise. Thus, there is a need for a more comprehensive assessment of HRQoL among this patient group to capture an additional source of variance in this important theoretical construct.

Keywords: Health-related quality of life, Personality, Latent state-trait analysis, HIV/AIDS

\section{Background}

Although a massive body of literature exists on the concept of well-being, including psychological well-being (PWB) (e.g. [1-6]), many controversies still exist with respect to the definition, the dynamics, and the implications of PWB on various areas of individual and social functioning [7]. One of these unresolved research questions is whether PWB should be viewed as a relatively stable trait throughout a person's life, or a trait subject to situational variability [8-12]. In other words, it is not clear how many variations in PWB are inherent in the person, and how many are tied to occasion-specific,

\footnotetext{
*Correspondence: marcin.rzeszutek@psych.uw.edu.pl

${ }^{1}$ Faculty of Psychology, University of Warsaw, Stawki 5/7, 00-183 Warsaw, Poland

Full list of author information is available at the end of the article
}

external factors. The first conceptualization is in line with several "top-down" theories of well-being, indicating a specific, mainly hereditary "set-point" level of wellbeing characteristic of individuals [13-15]. Conversely, "bottom-up" theories of well-being contend that it changes over time and is tied to various life events (e.g. [16-18]). Resolving the aforementioned controversy is of great importance not only for the theory, but also for the practical application of research on PWB, specifically the implementation of interventions to enhance PWB [19]. Nevertheless, until now, studies in this area mainly have been focused on one aspect of PWB, namely satisfaction with life (SWL), providing a rather coherent picture of the relatively stable nature of this cognitive component of PWB over time [9, 11, 20,21]. The temporal dynamics of other PWB components, including

(c) The Author(s). 2018 Open Access This article is distributed under the terms of the Creative Commons Attribution 4.0 International License (http://creativecommons.org/licenses/by/4.0/), which permits unrestricted use, distribution, and 
quality of life (QoL), are greatly underscored, referring especially to health-related quality of life (HRQoL) [22]. So far, previous research findings have been in favor of both a relatively consistent nature of HRQoL [23], as well as the notion that it may have some genetic basis [24] underlying its situational variability $[25,26]$. According to Sprangers and Schwartz [22], these conflicting results may be attributed to the multidimensional character of HRQoL, which consists of both changeable (e.g., emotional functioning) and relatively stable (e.g., physical functioning) domains. Thus, investigating the proportion of state vs. trait variance in HRQoL may be crucial, not only from theoretical point of view, but also for implementing successful interventions tailored for a specific area of a patient's functioning.

The aforementioned problem seems to be of special importance among people living with HIV (PLWH). On one hand, due to great advances in HIV treatment, HIV infection is now a chronic, manageable health problem [27, 28]. On the other hand, PLWH still struggle with intense HIVrelated distress originating from a wide variety of psychosocial stressors [29-35]. In addition, PLWH are reporting significantly lower HRQoL, not only compared with the general population, but also in comparison with other chronic diseases [36]. The literature on HRQoL among PLWH is huge, but very inconclusive [36-39], indicating the varying impact that clinical, and psychosocial factors may have on HRQoL. Importantly, whereas previous studies have spotlighted the major role of clinical variables in HRQoL among PLWH (e.g. [40]), an increasing number of researchers recently have highlighted psychosocial factors that may even outweigh the significance of medical factors [37, 41, 42].

Numerous authors have shown that PWB is influenced greatly by personality traits [43-46]. More specifically, Steel et al. [47], in a meta-analytic review, found that the variance in PWB explained by personality traits may range from $39 \%$ to as much as $63 \%$, which argument is used to support the hypothesis on the stability of PWB [48]. As far as PLWH are concerned, it was revealed that personality traits may be associated with some clinical variables, e.g., medication adherence (neuroticism negatively; [49]) and CD4 count (conscientiousness positively; [50]). However, the role of personality traits - e.g., neuroticism, extraversion, openness to experience, and conscientiousness - is especially profound for HRQoL in this patient group [49, 51-53]. Interestingly, Burgeous et al. [51] found that neuroticism had a strong impact on HRQoL that outweighed the role of health status, which is in line with a recent metaanalytic review conducted by Chan-Huang et al. [54], indicating that personality significantly affects HRQoL and that its effect is stronger than socio-demographic and medical variables.

\section{Current study}

Since most studies on PWB, and HRQoL in particular, among PLWH were conducted using a cross-sectional design [38], little is known about individual differences in HRQoL dynamics in this patient group, particularly the proportion of state vs. trait variance in HRQoL. Therefore, we conducted a longitudinal study to decompose variance of the repeated HRQoL measure into trait, state, and method components, and to verify the stability of HRQoL over time among participants. In addition, we wanted to examine whether the HRQoL trait component is related to personality traits, while controlling for selected socio-medical factors. Since we did not have newly diagnosed patients, but instead had those who had been under treatment for some time (see Table 1), we expected that the proportion of trait variance in HRQoL would be higher compared with the proportion of state variance after separation from domain-specific method variance. Secondly, for the same reason, we expected that overall HRQoL among participants would be stable for 12 months. Finally, based on the top-down theory, we hypothesized that the HRQoL trait component would be more strongly related to personality traits (e.g., neuroticism, extraversion, openness to experience, and conscientiousness) than to socio-medical factors.

\section{Method}

\section{Procedure}

Participants were recruited from patients at the outpatient clinic in the hospital of infectious diseases. After the informed consent was obtained, the participants completed a paper-and-pencil version of the inventories and participated in the study voluntary, as there was no remuneration for the participation. The study's eligibility criteria were as follows: age 18 years or older, medically diagnosed as HIV-positive, and currently receiving medical care from the clinic where the study was performed. The exclusion criteria included having HIV-related cognitive disorders diagnosed by psychiatrists working at the hospital. This study was approved by the ethics committee of the Faculty of Psychology, University of Finance and Management in Warsaw.

\section{Measures \\ Health-related quality of life}

Health-related quality of life (HRQoL) was assessed using the WHO Quality of Life-BREF (WHOQOLBREF), developed under a WHO initiative to assess this construct cross-culturally [55]. WHOQOL-BREF consists of 26 items used to measure four domains: somatic health, psychological health, social relationships, and environment. Higher values indicate higher quality of life in each domain. Cronbach's alpha coefficients for the current study ranged between .81 to .90 for somatic 
Table 1 Baseline Socio-Medical Characteristics of the Initial and Final Sample

\begin{tabular}{|c|c|c|}
\hline \multirow[t]{2}{*}{ Variable } & \multicolumn{2}{|l|}{ Sample } \\
\hline & $\begin{array}{l}\text { Initial } \\
N=141\end{array}$ & $\begin{array}{l}\text { Final } \\
N=82\end{array}$ \\
\hline \multicolumn{3}{|l|}{ Gender } \\
\hline Male & $120(85.1 \%)$ & $70(85.4 \%)$ \\
\hline Female & $21(14.9 \%)$ & $12(14.6 \%)$ \\
\hline \multicolumn{3}{|l|}{ Age in Years } \\
\hline $\mathrm{M} \pm \mathrm{SD}$ (Range) & $40.18 \pm 10.24(19-76)$ & $40.50 \pm 11.47(21-76)$ \\
\hline \multicolumn{3}{|l|}{ Stable relationship status } \\
\hline Yes & $84(59.6 \%)$ & $49(59.8 \%)$ \\
\hline No & $57(40.4 \%)$ & $33(40.2 \%)$ \\
\hline \multicolumn{3}{|l|}{ Education } \\
\hline Elementary/Secondary & $61(43.3 \%)$ & $31(37.7 \%)$ \\
\hline University degree & $80(56.7 \%)$ & $51(62.3 \%)$ \\
\hline \multicolumn{3}{|l|}{ Employment } \\
\hline Full employment & $99(70.2 \%)$ & $53(64.6 \%)$ \\
\hline Unemployment/Retirement & $42(29.2 \%)$ & $29(35.4 \%)$ \\
\hline \multicolumn{3}{|l|}{ HIV/AIDS status } \\
\hline HIV+ only & $120(85.1 \%)$ & $48(80.5 \%)$ \\
\hline HIV/AIDS & $21(14.9 \%)$ & $16(19.5 \%)$ \\
\hline \multicolumn{3}{|l|}{ HIV Infection Duration in Years } \\
\hline $\mathrm{M} \pm \mathrm{SD}$ (Range) & $7.34 \pm 6.20(1-30)$ & $7.39 \pm 5.72(1-30)$ \\
\hline \multicolumn{3}{|c|}{ Antiretroviral Treatment (ART) Duration in Years } \\
\hline $\mathrm{M} \pm \mathrm{SD}$ (Range) & $5.67 \pm 5.10(1-23)$ & $5.76 \pm 4.88(1-21)$ \\
\hline \multicolumn{3}{|l|}{ CD4 Count } \\
\hline $\mathrm{M} \pm \mathrm{SD}$ (Range) & $609.57 \pm 240.90(200-2000)$ & $645.73 \pm 256.23(200-2000)$ \\
\hline
\end{tabular}

$M$ Mean, SD Standard Deviation

domains for T1, T2 and T3; ranged between .75 to .88 for psychological domain for T1, T2 and T3; ranged between .69 to 83 for social domain for T1, T2 and T3; ranged between .80 to .86 for environmental domain for T1, T2 and T3.

\section{Personality dimensions}

Personality traits were measured with the NEO-FFI questionnaire by Costa and McCrae [56]. NEO-FFI consists of 60 items (12 per trait), to which participants responded on a five-point scale, from strongly disagree to strongly agree. Five indices were obtained: neuroticism, extraversion, openness to experience, agreeableness, and conscientiousness. The higher scores of each indicate on higher level of each trait. The Cronbach's alpha for the current study ranged for all traits from .76 to .82 at $\mathrm{T} 1, .72$ to .76 at $\mathrm{T} 2$ and .71 to .75 at T3.

\section{Data analysis}

To verify the research hypotheses, a latent state-trait (LST) analysis was performed $[57,58]$. The LST models have been used increasingly in analyses of longitudinal data to capture the within-time consistency vs. situation variability of individual differences of a particular variable over time. There are different versions of LTS models, but we applied the one described by Schermelleh-Engel et al. [59], in which a single trait is a second-order factor of state factors. Specifically, it was a single-construct model (HRQoL) with four indicators (HRQoL domains) measuring a latent trait repeatedly within six-month lags by three latent state variables. Also, as each domain was measured by a different part of the questionnaire, we added four method factors to capture a method-related variance. Thus, the LST model allowed for a breakdown of HRQoL variance into four parts: stable-trait variance, state-specific variance (expressed by latent state residuals), method variance, and error variance. It may help to specify how many variances of HRQoL among PLWH were explained by patient characteristics and how many by situation-specific fluctuations over time. The LST models differ from latent growth-curve (LGC) models, as these latter models 
may capture long-lasting and systematic changes within a particular variable over a long period of time. However, as our participants were not newly diagnosed patients, but had been infected and under treatment for some time already, we did not expect any significant systematic changes within HRQoL. Therefore, LST models were used instead of LGC models [58].

The IBM SPSS Statistics and AMOS, both version 24 [60], were used for data analysis, which consisted of three steps. The first step focused on testing measurement invariance [61] and calculating consistency, occasion specificity, and method specificity for each indicator [59], which provided information on indicator reliability. Next, latent mean changes were estimated to check whether HRQoL values changed over 12 months. Finally, individual values for trait factors were imputed and regressed on sociodemographic, clinical, and personality variables to answer the question of whether the HRQoL trait variable is related to other personal characteristics.

\section{Results}

\section{Study sample}

The first assessment was conducted during June and July 2016. A total of 141 patients agreed to take part in the study and provided their contact details (i.e., phone number and/or e-mail address). The second assessment was performed during January and February 2017. Out of 141 participants from the first assessment, 113 participated in the second assessment. The last assessment was performed during May and June 2017, with 82 participants remaining. Table 1 presents the sociomedical characteristics for both initial $(N=141)$ and final $(N=82)$ sample.

\section{Descriptive statistics and missing-data analysis}

The studied variables are present in Table 2. Results within HRQoL domains are relatively stable within the time frame. All the variables have a univariate skewness and kurtosis below values described by West et al. [62] as potentially problematic for multivariate normal distribution required for the maximum likelihood (ML) estimation. The Little's Missing Completely at Random $(\mathrm{MCAR})$ Test $($ chi-square $=53.832, \mathrm{df}=50, p=.330)$ indicated that the missing data were missing completely at random (MCAR, [63]), including socio-medical characteristics. Thus, to avoid a reduction in the statistical power of the study, we used ML estimation, available in AMOS, to impute the missing data [64]. Next, further analyses were done for all the participants who took part in the study, i.e., $N=141$.

\section{Measurement invariance and variance decomposition}

The goodness of fit of the model with configural invariance was satisfactory, $\mathrm{X}^{2}(39)=59.91, p=.02, \mathrm{X}^{2} / \mathrm{df}=1.54$, RMSEA $=.06,90 \%$ CI $[.03,0.9]$, CFI $=.979$, TLI $=.957$. Therefore, we checked whether the more constrained model with equal factor loadings of each domain variable on latent state variables fit significantly worse (weak factorial invariance). The comparison of models did not reject the assumption of weak factorial assumption

Table 2 Descriptive Statistics of The Studied Variables

\begin{tabular}{|c|c|c|c|c|c|c|}
\hline Variable & M & SD & Kurtosis & Skewness & Minimum & Maximum \\
\hline WHO_Somatic T1 & 25.21 & 4.93 & .80 & -.68 & 7 & 34 \\
\hline WHO_Somatic T2 & 25.10 & 5.16 & .35 & -.60 & 10 & 34 \\
\hline WHO_Somatic T3 & 24.06 & 5.51 & .43 & -.59 & 7 & 35 \\
\hline WHO_Psychological T1 & 22.70 & 3.93 & 1.54 & -.88 & 6 & 30 \\
\hline WHO_Psychological T2 & 22.51 & 3.94 & 1.13 & -.79 & 7 & 30 \\
\hline WHO_Psychological T3 & 21.43 & 4.64 & .15 & -.69 & 7 & 29 \\
\hline WHO_Social T1 & 11.33 & 2.28 & .13 & -.47 & 4 & 15 \\
\hline WHO_Social T2 & 11.06 & 2.58 & .69 & -.79 & 3 & 15 \\
\hline WHO_Social T3 & 10.43 & 2.63 & .49 & -.68 & 3 & 15 \\
\hline WHO_Enviromental T1 & 30.46 & 5.30 & 2.82 & -1.29 & 9 & 40 \\
\hline WHO_Enviromental T2 & 30.57 & 4.86 & 1.01 & -.75 & 13 & 40 \\
\hline WHO_Enviromental T3 & 29.73 & 5.62 & 1.91 & -.92 & 8 & 39 \\
\hline Neuroticims & 25.77 & 7.09 & -.24 & .02 & 7 & 44 \\
\hline Extraversion & 24.84 & 5.24 & 1.93 & -.92 & 2 & 35 \\
\hline Openness to experience & 23.94 & 5.90 & .16 & .06 & 6 & 37 \\
\hline Agreeableness & 28.81 & 6.19 & .54 & -.18 & 7 & 45 \\
\hline Conscientiousness & 27.43 & 5.13 & 1.09 & $-0,67$ & 7 & 37 \\
\hline
\end{tabular}

T1 First Assessment $(N=141), T 2$ Second Assessment $(B=113)$, T3 Third Assessment $(N=82)$ 
$(\mathrm{x} 2(6)=8.58, p=.199)$. Thus, next in hierarchy model with strong factorial invariance was tested with the intercepts of each domain equal within time and it did not fit the data significantly worse $\left(\chi^{2}(8)=9.33\right.$, $p=.315 ; \mathrm{\chi}^{2}(53)=77.81, p=.02, \mathrm{\chi}^{2} / \mathrm{df}=1.47$, RMSEA $=.06,90 \%$ CI $[.03,0.8], \mathrm{CFI}=.975$, TLI $=.962)$. It is presented in Fig. 1 as the final model, and variance components and reliability coefficients for its standardized solutions are provided in Table 3.

In general, reliability is satisfactory, albeit excluding social domain. A precision of measurement within this domain should be regarded as doubtful due to the lowest values and high variability between measurement points. The average consistency is the highest for psychological domain $(60 \%)$ and the lowest for social domain (45\%). Thus, the domains seem to be differently prone to occasion-specific influences. Also, we observed that $\mathrm{T} 1$ and $\mathrm{T} 3$ values across domains are affected by situation or person and situation interactions (as they are indistinguishable in the LTS models [58]), whereas T2 scores are more strongly linked to stable disposition $(52-81 \%)$, as well as method (12-43\%). Taken together, this may suggest problematic homogeneity of domain indicators. The occasion-specific variability is the most pronounced for $\mathrm{T} 1$, as 47 to $54 \%$ of individual differences in domain scores is due to the context of measurement. It is also clearly visible at the state level: Stable personal disposition ("trait") explains only $42 \%$ of interindividual differences in the overall $\mathrm{HRQoL}$ at $\mathrm{T} 1$, as many as $91 \%$ at T2, and $68 \%$ at T3. Thus, we observed substantial variability in a variance structure decomposition between domains, as well as within time.

\section{Latent mean change}

As the strong MI allows for mean comparison, for this purpose, the mean of the first latent state factor was fixed to be zero, whereas the means of the two remaining latent state factors were freed [58]. Consequently, the intercepts of those factors can be then interpreted as a difference relative to the first factor. For state at T2 (see Fig. 1), it was equal, -0.131 , and insignificant $(p=.722)$, whereas for state at T3, it was equal -0.993 , and significant $(p<.05)$. This indicates that although there was no change between $\mathrm{T} 1$ and $\mathrm{T} 2$, there was significant decrease in HRQoL level between T1 and T3.

\section{Time-invariant correlates of $\mathrm{HRQ} \mathrm{oL}$ trait component}

A three-step hierarchical regression with stepwise method of variables entry (probability of F; criteria: entry $=.5$ and removal $=.10$ ) was used to establish HRQoL trait (HRQoL-T) correlates. In the first step, sociodemographic variables were introduced (gender, age, education, employment, and relationship status). In the second step, variables related to HIV infection (CD4

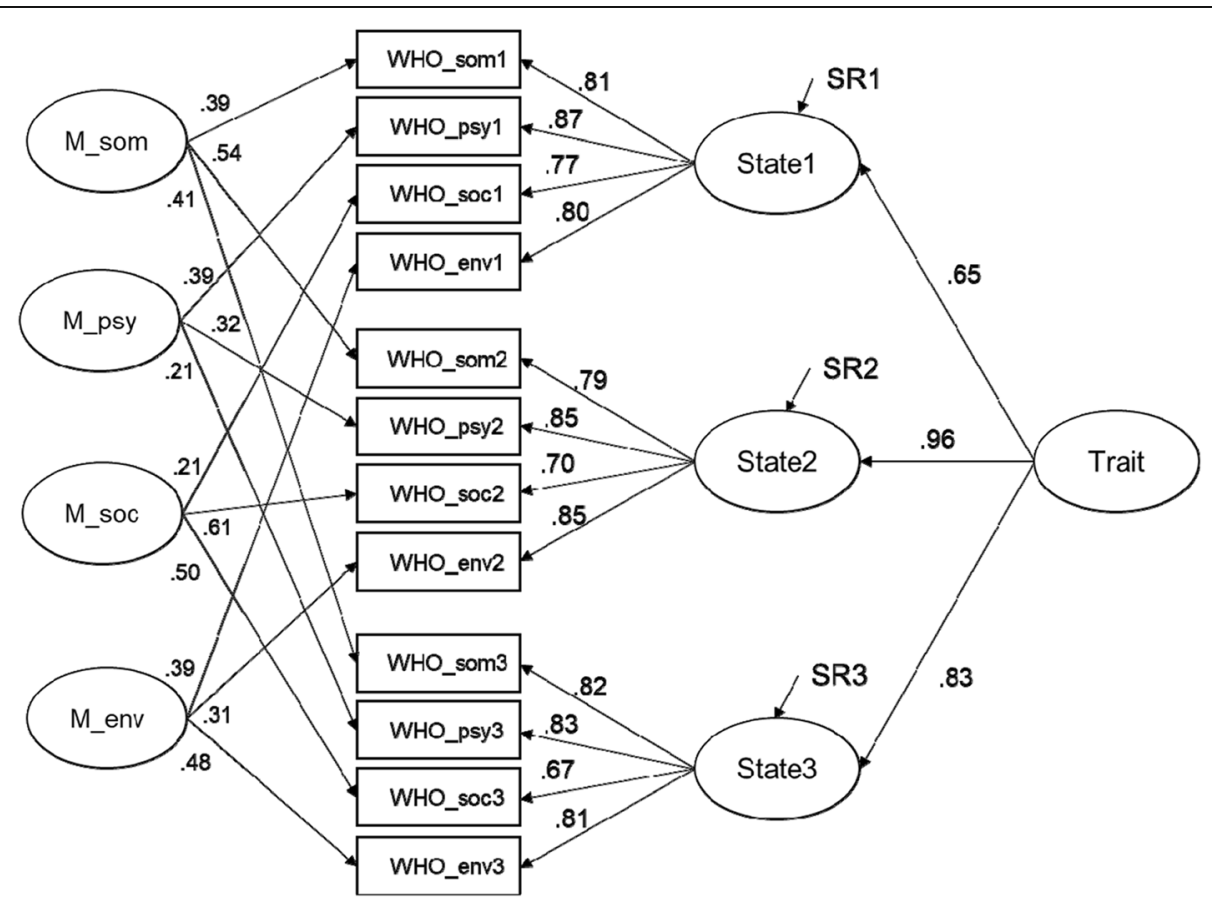

Fig. 1 The final latent state-trait-method model for three measurement points. Reported are standardized loading parameter estimates. Error terms of domain indicators are removed from the figure for sake of clarity. SR- latent state residuals; $\mathrm{M}$ - method factors; som - somatic domain of WHOQOL-BREF; psy - psychological domain of WHOQOL-BREF; soc. - social domain of WHOQOL-BREF; env - environmental domain of WHOQOL-BREF. Numbers 1, 2, 3 depict consecutive measurement points 
Table 3 Consistency, Occasion Specificity And Method Specificity For Each WHOQOL-BREF Domain

\begin{tabular}{|c|c|c|c|c|c|}
\hline Indicator & Consistency & Occasion specificity & Method Specificity & Reliability & Error \\
\hline \multicolumn{6}{|l|}{ Somatic Domain } \\
\hline WHO_Somatic T1 & .34 & .47 & .19 & .82 & .18 \\
\hline WHO_Somatic T2 & .62 & .06 & .32 & .92 & .08 \\
\hline WHO_Somatic T3 & .54 & .25 & .20 & .84 & .16 \\
\hline \multicolumn{6}{|l|}{ Psychological Domain } \\
\hline WHO_Psychological T1 & .35 & .49 & .16 & .91 & .09 \\
\hline WHO_Psychological T2 & .80 & .07 & .12 & .82 & .18 \\
\hline WHO_Psychological T3 & .64 & .30 & .06 & .73 & .27 \\
\hline \multicolumn{6}{|l|}{ Social Domain } \\
\hline WHO_Social T1 & .39 & .54 & .07 & .64 & .36 \\
\hline WHO_Social T2 & .52 & .05 & .43 & .86 & .14 \\
\hline WHO_Social T3 & .44 & .20 & .36 & .69 & .31 \\
\hline \multicolumn{6}{|l|}{ Enviromental Domain } \\
\hline WHO_Enviromental T1 & .34 & .47 & .19 & .81 & .19 \\
\hline WHO_Enviromental T2 & .81 & .08 & .12 & .81 & .19 \\
\hline WHO_Enviromental T3 & .50 & .24 & .26 & .88 & .12 \\
\hline
\end{tabular}

T1 First Assessment, T2 Second Assessment, T3 Third Assessment

count, time since HIV diagnosis, duration of ARV treatment, and HIV/AIDS status) were entered. Finally, Big Five personality dimensions were included in the model. All the explanatory variables were measured at $\mathrm{T} 1$, and categorical variables were dummy-coded. Due to a number of potentially inter-related variables, collinearity was checked; VIF was below 1.2. The results are presented in Table 4. Among sociodemographic variables, only being in a stable relationship and being employed were significant, but weak-positive correlates of HRQoL-T. None of the clinical variables was significantly related to HRQoL-T. After controlling for sociodemographic and clinical variables, neuroticism and extraversion significantly added to the model in the third step of the regression analysis. Their coefficients have the opposite sign, but have very similar strengths. Altogether, the correlates explain $26 \%$ of HRQoL-T variance.

\section{Discussion}

The results of the study were partly in line with the first research hypothesis, i.e., we showed that HRQoL among PLWH represents a stable trait to a somewhat greater extent than a situational variability, although the proportions were domain and time variant. More specifically, we noticed differences between particular HRQoL domains, i.e., psychological domain appeared to be the most consistent, whereas social domain appeared to be the most prone to situational influences. Although

Table 4 Results Of Three-Step Hierarchical Regression Analysis With Stepwise Method of Variables Entry and WHOQOL-BREF Trait Component as Explained Variable

\begin{tabular}{|c|c|c|c|c|c|c|}
\hline Model & $\mathrm{F}$ & df & $\Delta \mathrm{F}$ & $R^{2}$ & Adjusted $R^{2}$ & Beta \\
\hline Full Employment & $13.36^{* * *}$ & $1 ; 139$ & - & .29 & .08 & $.29 * * *$ \\
\hline Full Employment & $11.13^{* * *}$ & $1 ; 138$ & $8.20^{* * *}$ & .37 & .13 & $.24^{* * *}$ \\
\hline + Stable Relationship & & & & & & $.23^{* * *}$ \\
\hline Full Employment & $1.56^{* * *}$ & $1 ; 137$ & $.8 .24^{* * *}$ & .43 & .18 & $.20^{* *}$ \\
\hline Stable Relationship & & & & & & $.21^{* * *}$ \\
\hline + Extraversion & & & & & & $.23^{* * *}$ \\
\hline Full Employment & $13.22^{* * *}$ & $1 ; 136$ & $17.40^{* * *}$ & .53 & .26 & $.19^{* *}$ \\
\hline Stable Relationship & & & & & & $.21^{* *}$ \\
\hline Extraversion & & & & & & $.34^{* * *}$ \\
\hline + Neuroticism & & & & & & $-.32^{* * *}$ \\
\hline
\end{tabular}

*** $p<.001 ;{ }^{* *} p<.01$ 
several longitudinal studies have recently been conducted on HRQoL among PLWH (e.g. [37, 39]), none of them, to our best knowledge, has used the LST model. Thus, we do not have a direct benchmark to compare our results within this specific study design. However, our findings may have important theoretical and practical implications, as HRQoL is becoming a widely accepted patient-reported outcome in HIV research and counselling, as it may provide information that's often difficult to obtain in clinical analysis [42]. Therefore, it is vital for HIV/AIDS health services to know which areas of HRQoL among PLWH should be addressed upfront in psychological interventions [65].

On one hand, consistency of psychological domain and occasion specificity of social aspects of HRQoL may suggest that the former is more person-rooted and the latter is a more situation-derived aspect of HRQoL. As such, they should be addressed differently in psychological interventions, first by person-oriented interventions (e.g., cognitive, behavioral interventions; [66]), and second by more interpersonal-focused techniques [67]. But other explanations also must be considered in the case of social domain of HRQoL. Namely, it was measured by the shortest three-item-only scale, which turned out to be unreliable enough among PLWH. Specifically, it includes a potentially sensitive item (i.e., How satisfied are you with your sex life?), which, in such a group, may measure different things during different stages in HIV patients' lives, so the scores may be blurred by time-variant heterogeneity of the item interpretation, not by a situation itself. Thus, WHOQQLBREF reliability of measurement calls for improvement in social domain, at least as far as PLWH are considered.

We also observed that HRQoL was relatively stable over time among participants, which was in line with our second hypothesis. Specifically, the aforementioned results also should be seen within the context of our sample, i.e., highly functional PLWH who have been undergoing antiretroviral therapy (ART) for some time already, and due to it have a mean CD4 count similar to that of the healthy population [68]. It also may shed some light on why clinical variables were unrelated to HRQoL among our participants, which has been noted in recent studies [41]. On a general level, this finding may be interpreted as a great advance in HIV/AIDS knowledge and treatment, as new advances have reduced HIV infections from a terminal and fatal disease to a chronic and manageable health condition [27]. It seems that nowadays, HIV infection does not entail serious psychological disturbances, as great progress in ART has provided opportunities for PLWH to live a longer life and has enabled successful adaptation to this disease [28].
Finally, personality traits, e.g., neuroticism and extraversion, appeared to be more strongly associated with trait components of HRQoL when compared with sociomedical data, which corresponded with our third hypothesis. Importantly, out of all the socio-medical data in our study, only being employed and being in a stable relationship were significantly related to the consistency of HRQoL, a finding that has been noted by other authors $[69,70]$. In discussing this finding in the context of the trait-state conceptualization of well-being, it should be mentioned that these two personality traits predicted the highest proportion of stability of wellbeing among different study samples, even over a long period of time [14, 21]. Additionally, this finding is in line with the recent meta-analysis conducted by ChanHuang et al. [54], who observed that personality outweighs the significance of socio-medical data in predicting HRQoL. Aforementioned results, therefore, are in line with HIV/AIDS literature on the role of personality traits and HRQoL. Neuroticism, in particular, predicted poorer HRQoL, mainly in psychological domains and independent of health status [51, 71]. Extraversion was positively related to HRQoL, especially within domains describing overall happiness and satisfaction from life, HIV mastery, and sexual functioning [49]. Nevertheless, existing studies are scarce and cross-sectional, so our research added to the literature by examining personality as a correlate of HRQoL consistency among PLWH in a longitudinal study design. Although these relationships are weak, which clearly implies a uniqueness of HRQoL measurement over personality assessment, clinicians perhaps should consider the role of personality in implementing successful psychosocial interventions to enhance HRQoL among PLWH. For instance, it was demonstrated that personality traits may impact HRQoL among different patient groups [54]. Specifically, personality indirectly changes $\mathrm{HRQ} O \mathrm{~L}$ by influencing the process of coping with illness [72] and illness appraisal [73]. Several studies conducted among PLWH showed that coping and appraisal are crucial to the success of psychosocial interventions $[65,74,75]$.

\section{Strengths and limitations}

This study has a few strengths, namely longitudinal and theory-driven study design, as well as examination of consistency of HRQoL among a high-risk sample, i.e., PLWH. However, a few limitations should be mentioned. First, the sample was relatively small, and there was comparatively high dropout. In addition, the sample consisted of highly functional PLWH with good medical control of HIV infection, predominantly men. Furthermore, due to organizational reasons, the sample was diverse in terms of HIV-infection duration. It is therefore likely that other results would be obtained in a sample 
with a different gender ratio or/and clinical characteristics, especially concerning the stability of HRQoL. On the other hand, as was mentioned before, our participants were rather homogenous with regard to socio-medical variables, and dropout was a random factor that should not be viewed as systematic selection bias. Furthermore, we observed high variability in variance structure decomposition of HRQoL, as well as the high percentage of remaining variance in its trait component - this should be the subject of further studies. Finally, we used WHOQOL-BREF instead of WHOQOL-HIV-BREF, as at the time of conducting this study there was no Polish version of the WHOQOL-HIV-BREF. Nevertheless, WHOQOL-BREF was also used extensively among HIV/AIDS population and proved to be a reliable and a valid instrument to assess HRQoL also in this patient group [76-78].

\section{Conclusions}

There is a consistency in HRQoL among PLWH, but also substantial occasion and method specificity that also vary between domains and within time. Specifically, the social domain indicator in WHOQQL-BREF can be regarded as unreliable, which should be considered when using the tool. Conversely, psychological domain is the most consistent, therefore it represents mainly stable personal disposition. In addition, HRQoL among PLWH is rather distinct from personality and sociomedical data, i.e., personality traits and socio-medical data altogether explained $26 \%$ of variance in the HRQoL trait component, indicating a uniqueness of HRQoL assessment in clinical practice. Thus, there is a need for more in-depth analyses of HRQoL evaluations to cover these patients' substantial individual differences that are not attributable to their personality, medical, or sociodemographic characteristics.

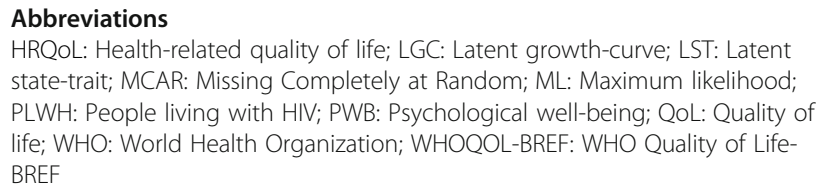
state-trait; MCAR: Missing Completely at Random; ML: Maximum likelihood; PLWH: People living with HIV; PWB: Psychological well-being; QoL: Quality of life; WHO: World Health Organization; WHOQOL-BREF: WHO Quality of LifeBREF

\section{Acknowledgements}

The authors thank medical doctors from Warsaw's Hospital for Infectious Diseases for help in participants' recruitment process.

\section{Funding}

This work was supported by the University of Warsaw, Faculty ofPsychology under Grant BST181409/2017.

\section{Availability of data and materials}

The datasets used and/or analysed during the current study available from the corresponding author on reasonable request.

\section{Authors' contributions}

MR was the main investigator, who designed the study, collected the data, wrote the paper and participating in data analysis. EG participated in the study design, analysed and interpreted the data and revised the final draft. Both authors read and approved the final manuscript.

\section{Ethics approval and consent to participate}

All procedures performed in studies involving human participants were in accordance with the ethical standards of the institutional and/or national research committee and with the 1964 Helsinki declaration and its later amendments or comparable ethical standards. This study was approved by the ethics committee of the Faculty of Psychology, University of Finance and Management in Warsaw. All participants sing informed consent.

\section{Competing interests}

The authors declare that they have no competing interests.

\section{Publisher's Note}

Springer Nature remains neutral with regard to jurisdictional claims in published maps and institutional affiliations.

\section{Author details}

${ }^{1}$ Faculty of Psychology, University of Warsaw, Stawki 5/7, 00-183 Warsaw, Poland. 'Faculty of Psychology, University of Social Sciences and Humanities, Chodakowska 19/31, 03-815 Warsaw, Poland.

Received: 13 December 2017 Accepted: 8 May 2018

Published online: 24 May 2018

\section{References}

1. Constanza R, Fisher B, Ali S. Quality of life: an approach integrating opportunities, human needs, and subjective wellbeing. Ecol Econ. 2007;61: 267-76. doi.org/10.1016/j.ecolecon.2006.02.023

2. Diener E. Subjective well-being. In: Diener E, editor. The science of wellbeing. New York: Spring; 2009. p. 11-58.

3. Diener E, Oishi S, Ryan K. Universals and cultural differences in the causes and structure of happiness: a multilevel review. In: Keyes C, editor. Mental well-being. Dordrecht: Springer; 2010. p. 153-76.

4. Ryff C. Happiness is everything, or is it? Explorations on the meaning of psychological well-being. J Pers Soc Psychol. 1989;57:1069-81. https://doi. org/10.1037/0022-3514.57.6.1069

5. Ryff C. Psychological well-being revisited: advances in the science and practice of Eudaimonia. Psychother Psychosom. 2014;83:10-28. https://doi. org/10.1159/000353263.

6. Steptoe A, Deaton A, Stone A. Subjective wellbeing, health, and ageing. Lancet. 2015;14:640-8.

7. Diener E, Heintzelman S, Kushlev K, Tay L, Wirtz D, Lutes L, Oishi S. Findings All Psychologists Should Know From the New Science on Subjective WellBeing. Canad Psychol. 2016;58(2):87-104. https://doi.org/10.1037/ cap0000063

8. Brockman H, Delhey J. Introduction: the dynamics of happiness and the dynamics of happiness research. Soc Indic Res. 2010;97:1-5. https://doi.org/ 10.1007/s11205-009-9561-3.

9. Eid M, Diener E. Global judgments of subjective well-being: situational variability and long-term stability. Soc Indic Res. 2004;65:245-77. https://doi. org/10.1023/B:SOCl.0000003801.89195.bc.

10. Kaczmarek $\measuredangle$, Bujacz A, Eid M. Comparative latent state-trait analysis of satisfaction with life measures: the Steen happiness index and the satisfaction with life scale. J Happ Stud. 2015;16:443-53. https://doi.org/10. 1007/s10902-014-9517-4.

11. Li Z, Yin X, Jiang S, Wang M, Cai T. Psychological mechanism of subjective well-being: a stable trait or situational variability. Soc Indic Res. 2014;118: 523-34. https://doi.org/10.1007/s11205-013-0449-x.

12. Lyubomirsky S, Lepper $\mathrm{H}$. A measure of subjective happiness: preliminary reliability and construct validation. Soc Indic Res. 1999;46:137-55. https://doi. org/10.1023/A:1006824100041.

13. Brickman P, Campbell D. Hedonic relativism and planning the good society. In: Appley MH, editor. Adaptation level theory. New York: Academic Press; 1971

14. Costa P, McCrae R. Influences of extraversion and neuroticism on subjective well-being. J Pers Soc Psychol. 1980;38:668-78. PMID: 7381680

15. Cummins R. On the trail of the gold standard for life satisfaction. Soc Indic Res. 1995;35:179-200. https://doi.org/10.1007/BF01079026. 
16. Veenhoven R. Is happiness a trait? Soc Indic Res. 1994;32:101-60. https://doi. org/10.1007/BF01078732

17. Lyubomirsky S, Sheldon K, Schkade D. Pursuing happiness: the architecture of sustainable change. Rev Gen Psychol. 2005;9:111-31. https://doi.org/10. 1037/1089-2680.9.2.111.

18. Odou N, Vella-Brodrick D. The efficacy of positive psychology interventions to increase well-being and the role of mental imagery ability. Soc Indic Res. 2013;110:111-29. https://doi.org/10.1007/s11205-011-9919-1.

19. Howell R, Kern M, Lyubomirsky S. Health benefits: meta-analytically determining the impact of well-being on objective health outcomes. Health Psychol Rev. 2007;1:83-136. https://doi.org/10.1080/17437190701492486

20. Fujita F, Diener E. Life satisfaction set point: stability and change. J Pers Soc Psychol. 2005;88:158-64. https://doi.org/10.1037/0022-3514.88.1.158.

21. Lucas R, Diener E. Subjective well-being. Handbook of emotions. In: Lewis M, Haviland-Jones J, editors. Handbook of emotions. 3rd ed. New York: Guilford; 2008. p. 471-84

22. Sprangers $M$, Schwartz C. Reflections on changeability versus stability of health-related quality of life: distinguishing between its environmental and genetic components. Health Qual Life Out. 2008;6:89. https://doi.org/10. 1186/1477-7525-6-89

23. Learmonth Y, Alwick E, McAuley E, Mot R. Quality of life and health-related quality of life over 1 year in older women: monitoring stability and reliability of measurement. Soc Indic Res. 2015;123:267-79. https://doi.org/10.1007/ s11205-014-0729-0

24. Sloan J, Xinghua Z. Genetics and quality of life. Curr Problem Cancer. 2006; 30:255-60. https://doi.org/10.1016/j.currproblcancer.2006.09.001.

25. Beisland E, Aarstad A, Osthus A, Aarstad H. Stability of distress and health related quality of life as well as relation to neuroticism, coping and TNM stage in head and neck cancer patients during follow-up. Act Oto-Laryng. 2013;133:209-17. https://doi.org/10.3109/00016489.2012.720032.

26. Lorenz K, Cunningham W, Spritzer K, Hays R. Changes in symptoms and health-related quality of life in a nationally representative sample of adults in treatment for HIV. Qual Life Res. 2006;15:951-8. https://doi.org/10.1007/ s11136-005-6010-X

27. Deeks S, Lewin S, Havlir D. The end of AIDS: HIV infection as a chronic disease. Lancet. 2013;382:1525-33. https://doi.org/10.1016/S01406736(13)61809-7

28. Samji H, Cescon A, Hogg R, Modur S, Althoff K. Closing the gap: increases in life expectancy among treated HIV-positive individuals in the United States and Canada. PLoS One. 2013:18:144-56.

29. Adewuya A, Afolabi M, Ola B, Ogundele O, Ajibare A, Oladipo B, Fakande I. Post-traumatic stress disorder (PTSD) after stigma related events in HIV infected individuals in Nigeria. Soc Psychiat Psychiat Epidem. 2009;44:761-6. https://doi.org/10.1007/s00127-009-0493-7.

30. Bogart L, Wagner G, Galvan F, Landrine H, Klein D. Perceived discrimination and mental health symptoms among black men with HIV. Cultural diversity and ethnic minority. Psychol. 2011;17:295-302. https://doi.org/10.1037/ a0024056

31. Emlet C. A comparison of HIV stigma and disclosure patterns between older and younger adults living with HIV/AIDS. AIDS Patient Care STDs. 2006;20: 350-8.

32. Hansen N, Vaughan E, Cavanaugh C, Connell C, Sikkema K. Health-related quality of life in bereaved HIV-positive adults: relationships between HIV symptoms, grief, social support, and Axis II indication. Health Psychol. 2009; 28:249-57. https://doi.org/10.1037/a0013168

33. Pantalone $D$, Hessler $D$, Simoni J. Mental health pathways from interpersonal violence to health-related outcomes in HIV-positive sexual minority men. J Cons Clin Psychol. 2010;78:387-97. https://doi.org/10.1037/ a0019307.

34. Rzeszutek M, Oniszczenko W, Firląg-Burkacka E. Temperament traits, coping style and trauma symptoms in HIV+ men and women. AIDS Care. 2012;24: 1150-4. https://doi.org/10.1080/09540121.2012.687819.

35. Rzeszutek M, Oniszczenko W, Firląg-Burkacka E. Gender differences in posttraumatic stress symptoms and the level of posttraumatic growth among a polish sample of HIV-positive individuals. AIDS Care. 2016;28: $1411-5$

36. Miners A, Phillips A, Kreif N, Rodger A, Speakman A, Fisher M, Anderson J, Collins S. Hart G, Sherr L, Lampe F. Health-related quality-of-life of people with HIV in the era of combination antiretroviral treatment: a cross-sectional comparison with the general population. Lancet HIV 2014; e32-e40. doi: https://doi.org/10.1016/S2352-3018(14)70018-9.
37. Lifson A, Grund B, Gardner E, et al. Improved quality of life with immediate versus deferred initiation of antiretroviral therapy in early asymptomatic HIV infection. AIDS. 2017;31:953-63.

38. Cooper V, Clatworthy J, Harding R, Whetham J, Consortium E. Measuring quality of life among people living with HIV: a systematic review of reviews. Health Qual Life Out. 2017;15:220.

39. Torres T, Harrison L, La Rosa A, et al. Quality of life improvement in resource-limited settings after one year of second-line antiretroviral therapy use among adult men and women. AIDS. 2018;32:583-93.

40. Burgoyne R, Saunders D. Quality of life among urban Canadian HIV/AIDS clinic outpatients. Int J STD AIDS. 2001;12:505-12. https://doi.org/10.1328/ a03564056.

41. Ballester-Arnal R, Martínez S, Fumaz C, González-García G, Remor E, Fuste M. A Spanish study on psychological predictors of quality of life in people with HIV. AIDS Behav. 2016;20:281-91. https://doi.org/10.1007/s10461-015-1208-6.

42. Oberjé E, Dima A, van Hulzen A, Prins J, de Bruin M. Looking beyond health-related quality of life: predictors of subjective well-being among people living with HIV in the Netherlands. AIDS Behav. 2015;19:1398-407. https://doi.org/10.1007/s10461-014-0880-2.

43. DeNeve K, Cooper H. The happy personality: a meta-analysis of 137 personality traits and subjective well-being. Psychol Bull. 1998;124:197-229. https://doi.org/10.1037/0033-2909.124.2.19.

44. Husson O, Vissers P. Denollet J, Mols F. The role of personality in the course of health-related quality of life and disease-specific health status among colorectal cancer survivors: a prospective population-based study from the PROFILES registry. Act Oncol. 2015;54:669-77. https://doi.org/10.3109/ 0284186X.2014.996663.

45. Whitworth S, Loftus A, Skinner T, Gasson N, Barker R, et al. Personality affects aspects of health-related quality of life in Parkinson's disease via psychological coping strategies. J Parkin Disease. 2013;3:45-53. https://doi. org/10.3233/JPD-120149.

46. Weiss $\mathrm{A}$, Bates T, Luciano M. Happiness is a personal(ity) thing: the genetics of personality and well-being in a representative sample. Psychol Sci. 2008; 19:205-10. https://doi.org/10.1111/j.1467-9280.2008.02068.x.

47. Steel P, Schmidt J, Shultz J. Refining the relationship between personality and subjective well-being. Psychol Bull. 2008;134:138-61. https://doi.org/10. 1037/0033-2909.134.1.138.

48. Lucas R, Donnellan M. Estimating the reliability of single-item life satisfaction measures: results from four national panel studies. Soc Indic Res. 2012;105:323-31. https://doi.org/10.1007/s11205-011-9783-z.

49. Penedo F, Gonzalez J, Dahn J, Antoni M, Malow R, Costa P, Schneiderman N. Personality, quality of life and HAART adherence among men and women living with HIV/AIDS. J Psychosom Res. 2003;54:271-8. https://doi. org/10.1016/S0022-3999(02)00482-8

50. O'Cleirigh C, Ironson G, Weiss A, Costa T. Conscientiousness predicts disease progression (CD4 number and viral load) in people living with HIV. Health Psychol. 2007;26:473-80. doi.org/10.1037/0278-6133.26.4.473

51. Burgess A, Carretero M, Elkington A, Pasqual-Marsettin E, Lobacaro C, Catalan J. The role of personality, coping style and social support in health related quality of life in HIV infection. Qual Life Res. 2000;9:423-37. https:// doi.org/10.1023/A:1008918719749.

52. Ironson $\mathrm{G}$, Hayward $\mathrm{H}$. Do positive psychosocial factors predict disease progression in HIV-1? A review of the evidence. Psychosom Med. 2008;70: 546-54. https://doi.org/10.1097/PSY.0b013e318177216c.

53. Lockenhoff C, Ironson G, O'Cleirigh C, Costa P. Five-factor mode personality traits, spirituality, religiousness, and mental health among people living with HIV. J Pers. 2009;77:1411-36. https://doi.org/10.1111/j. 1467-6494.2009.00587.x.

54. Chan Huang I, Lee J, Ketheeswaran P, Jones C, Revicki D, Wu A. Does personality affect health-related quality of life? A systematic review PLoS One. 2017;12:e0173806. https://doi.org/10.1371/journal.pone.0173806

55. WHOQOL Group. WHOQOL group, the World Health Organization quality of life assessment: position paper from the World Health Organization. Soc Sci Med. 1995:41:1403-9.

56. Costa PT, McCrae RR. Revised NEO personality inventory (NEO-PI-R) and NEO five-factor inventory (NEO-FFI) professional manual. Odessa, FL: Psychological Assessment Resources; 1992.

57. Eid M. Latent class models for analysing variability and change. In: Ongand A, van Dulmen M, editors. Handbook of methods in positive psychology. Oxford: Oxford University Press; 2007. p. 591-607. https://doi.org/10.1457// 056-6133.2045. 
58. Geiser C, Bishop J, Lockhart G, Shiffman S, Grenard J. Analyzing latent statetrait and multiple-indicator latent growth curve models as multilevel structural equation models. Front Psychol. 2013;4:975. https://doi.org/10. 3389/fpsyg.2013.00975.

59. Schermelleh-Engel K, Keith N, Moosbrugger H, Hodapp V. Decomposing person and occasion-specific effects: an extension of latent state-trait (LST) theory to hierarchical LST models. Psychol Meth. 2004;9:198-219. https://doi. org/10.1037/1082-989X.9.2.198.

60. IBM Corp. IBM SPSS statistics for windows. Version 24. Armonk, NY: IBM Corp; 2016.

61. Meredith W, Horn J. The role of factorial invariance in modeling growth and change. In: Collins LM, Sayer A, Collins L, Sayer A, editors. New methods for the analysis of change. Washington, DC, US: American Psychological Association; 2001. p. 203-40. https://doi.org/10.1037/10409-007.

62. West S, Finch J, Curran P. Structural equation models with nonnormal variables. Problems and remedies. In: Hoyle R, editor. Structural equation modeling: concepts, issues and applications. Newbury Park, CA: Sage; 1995. p. $56-75$.

63. Graham J. Missing data analysis: making it work in the real world. Ann Rev Psychol. 2009;60:549-76. https://doi.org/10.1146/annurev.psych.58.110405. 085530.

64. Shin T, Davison M, Long J. Maximum likelihood versus multiple imputation for missing data in small longitudinal samples with nonnormality. Psychol Methods. 2016; https://doi.org/10.1037/met0000094.

65. Wu L, Li X. Community-based HIV/AIDS interventions to promote psychosocial well-being among people living with HIV/AIDS: a literature review. Health Psychol Behav Med. 2013;1:31-46. https://doi.org/10.1080/ 21642850.2013.822798.

66. Brown J, Vanable P. Cognitive-behavioral stress management interventions for persons living with HIV: a review and critique of the literature. Ann Behav Med. 2008;35:26-40. https://doi.org/10.1007/s12160-007-9010-y.

67. Roopnaraine T, Rawat R, Babirye F, Ochai R, Kadiyala S. "The group" in integrated HIV and livelihoods programming: opportunity or challenge? AIDS Care. 2012;24:649-57. https://doi.org/10.1080/09540121.2011.630349.

68. European AIDS Clinical Society (EACS) guidelines. Version 8.2 January 2017 http://www.eacsociety.org/guidelines/eacs-guidelines/eacs-guidelines.html.

69. Abramowitz S, Koenig L, Chandwani S, Orban L, Stein L. Characterizing social support: global and specific social support experiences of HIVinfected youth. AIDS Patient Care STDs. 2009;23:323-30. https://doi.org/10. 1089/apc.2008.0194.

70. Mavandadi S, Zanjani F, Have T, Oslin D. Psychological wellbeing among individuals aging with HIV: the value of social relationships. J Acq Imm Defic Synd. 2009;51:91-8. https://doi.org/10.1097/QAl.0b013e318199069b.

71. Talukdar A, Ghosal M, Sanyal D, Basu S. Determinants of quality of life in HIV-infected patients receiving highly active antiretroviral treatment at a medical college ART Center in Kolkata, India. J Inter Assoc Physic AIDS Care. 2012;12(4):284-90. https://doi.org/10.1177/1545109712445924.

72. Diener E, Oishi S, Lucas R. Personality, culture, and subjective well-being: emotional and cognitive evaluations of life. Ann Rev Psychol. 2003;54:40325. https://doi.org/10.1146/annurev.psych.54.101601.145056.

73. Wrosch C, Scheier M. Personality and quality of life: the importance of optimism and goal adjustment. Qual Life Res. 2003;12:59-72. https://doi.org/ 10.1023/A:1023529606137.

74. Shai N, Sikweyiya Y, van der Heijden I, Abrahams N, Jewkes R. "I was in the darkness but the group brought me light": development, relevance and feasibility of the Sondela HIV adjustment and coping intervention. PLOS One. 2017;12(6):e0178135. https://doi.org/10.1371/journal.pone.0178135

75. Sikkema K, Kelly J. Behavioral medicine interventions can improve the quality-of-life and health of persons with HIV disease. Ann Behav Med. 1996; 18:40-8. https://doi.org/10.1007/BF02903938

76. Fang C, Hsiung P, Yu C, Chen M, Wang J. Validation of the World Health Organization quality of life instrument in patients with HIV infection. Qual Life Res. 2002;11:753-62. https://doi.org/10.1023/A:1020870402019.

77. Hou W, Chen C, Liu H, Lai Y, Lee H, Lee N, Chang C, Chen P, Ko W, Shu B, Ko N. Mediating effects of social support on depression and quality of life among patients with HIV infection in Taiwan. AIDS Care. 2014;26:996-1003. https://doi.org/10.1080/09540121.2013.873764.

78. Ping-Chuan H, Chi-Tai F, Yu-Yin C, Mao-Yen C, Jung-Der W. Comparison of WHOQOL-BREF and SF-36 in patients with HIV infection. Qual Life Res. 2005; 14:141-50. https:/doi.org/10.1007/s11136-004-6252.

\section{Ready to submit your research? Choose BMC and benefit from:}

- fast, convenient online submission

- thorough peer review by experienced researchers in your field

- rapid publication on acceptance

- support for research data, including large and complex data types

- gold Open Access which fosters wider collaboration and increased citations

- maximum visibility for your research: over $100 \mathrm{M}$ website views per year

At BMC, research is always in progress.

Learn more biomedcentral.com/submissions 